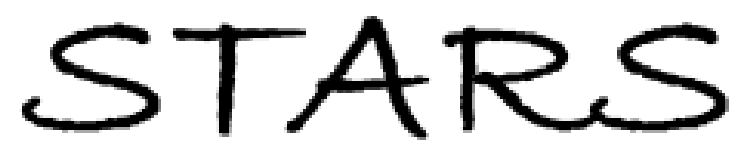

University of Central Florida

STARS

$1-1-2014$

\title{
A one-parameter Budyko model for water balance captures emergent behavior in darwinian hydrologic models
}

Dingbao Wang

University of Central Florida

Yin Tang

University of Central Florida

Find similar works at: https://stars.library.ucf.edu/facultybib2010 University of Central Florida Libraries http://library.ucf.edu

This Article is brought to you for free and open access by the Faculty Bibliography at STARS. It has been accepted for inclusion in Faculty Bibliography 2010 s by an authorized administrator of STARS. For more information, please contact STARS@ucf.edu.

\section{Recommended Citation}

Wang, Dingbao and Tang, Yin, "A one-parameter Budyko model for water balance captures emergent behavior in darwinian hydrologic models" (2014). Faculty Bibliography 2010s. 6244.

https://stars.library.ucf.edu/facultybib2010/6244

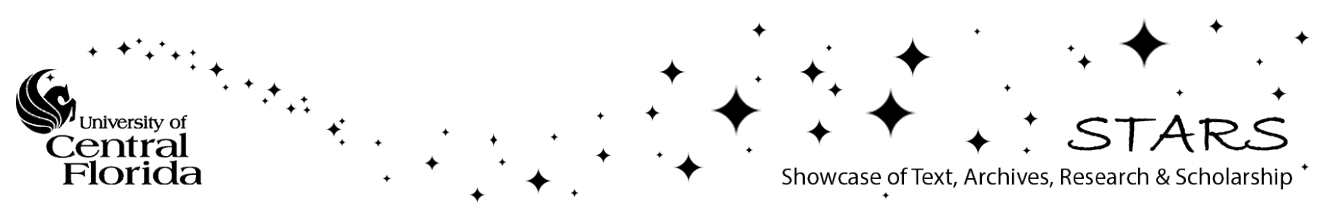




\section{Geophysical Research Letters}

\section{RESEARCH LETTER}

10.1002/2014GL060509

Key Points:

- Commonality of Budyko, abcd, and SCS models across time scales

- Derived a single-parameter

Budyko equation from

generalized proportionality

- A lower bound above the horizontal axis is identified for Budyko curve

Correspondence to:

D. Wang,

dingbao.wang@ucf.edu

\section{Citation:}

Wang, D., and Y. Tang (2014), A oneparameter Budyko model for water balance captures emergent behavior in darwinian hydrologic models, Geophys. Res. Lett., 41, 4569-4577, doi:10.1002/2014GL060509.

\section{Received 13 MAY 2014} Accepted 10 JUN 2014 Accepted article online 16 JUN 2014 Published online 2 JUL 2014

\section{A one-parameter Budyko model for water balance captures emergent behavior in darwinian hydrologic models}

\author{
Dingbao Wang' and Yin Tang' \\ ${ }^{1}$ Department of Civil, Environmental, and Construction Engineering, University of Central Florida, Orlando, Florida, USA
}

\section{Introduction}

In hydrologic problems, conservation of mass (i.e., water balance) should always hold regardless of the time scale of interest. Yet, identifying the water balance behavior over various temporal scales remains a challenging research task. One reason for this is that the roles of controlling factors on rainfall partitioning vary with temporal scale. For example, rainfall intensity and topography are important factors for runoff generation at short-time scales [Dunne and Black, 1970; Beven and Kirkby, 1979], while climate aridity index is the dominant controlling factor affecting the ratio between evaporation and precipitation [Budyko, 1974]. To deal with this problem, various conceptual hydrologic models have been developed for capturing these dominant controls on rainfall partitioning specific to a particular temporal scale, i.e., long-term, monthly, or event scale [Blöschl and Sivapalan, 1995].

Hydrologic models can be categorized as being either Newtonian or Darwinian. The Newtonian approach builds a mechanistic model of hydrologic processes (e.g., evaporation, infiltration, surface runoff, and base flow) and their coupled components including initial conditions, boundary conditions, and model parameters. Hydrologic behavior is derived from Newton's laws of motion, specifically the momentum equation, and other conservation equations (mass and energy). For example, the infiltration process can be modeled by the Richards equation, which combines the continuity equation with Darcy's law, which represents the momentum equation. The Darwinian approach is not concerned with the physical processes in isolation and instead aims to explain the hydrologic behavior as a system [Harman and Troch, 2014]. The Darwinian approach involves identifying simple and robust spatial or temporal patterns in hydrologic behavior from a population of watersheds and postulating a theory for connecting the observed patternsboth similarities and variations - to the processes that created them [Harman and Troch, 2014]. Spatial or temporal patterns are also called emergent behaviors in complex systems, and many examples, such as self-similar phenomena, are encountered in other fields of the geophysical sciences [Harte, 2002; Gentine et al., 2010].

The Darwinian approach is exemplified by three hydrologic models, which were developed based on empirical data from a large number of watersheds: the Budyko curve for long-term or climatological water 
Table 1. Three Budyko-Type Equations With a Single-Parameter

\begin{tabular}{lcc} 
Budyko-type Equations & Parameter & References \\
\hline$\frac{E}{P}=\left[1+\left(\frac{E_{P}}{P}\right)^{-n}\right]^{-1 / n}$ & $n$ & $\begin{array}{c}\text { [Turc, 1954; Mezentsev, 1955; Pike, 1964; } \\
\text { Choudhury, 1999; Yang et al., 2008] }\end{array}$ \\
$\frac{E}{P}=1+\frac{E_{p}}{P}-\left[1+\left(\frac{E_{p}}{P}\right)^{\omega}\right]^{1 / \omega}$ & $\omega$ & {$[$ [Fu, 1981; Zhang et al., 2004; Yang et al., 2007] } \\
$\frac{E}{P}=\frac{1+w \frac{E_{p}}{P}}{1+w \frac{E_{p}}{P}+\left(\frac{E_{p}}{P}\right)^{-1}}$ & $w$ & [Zhang et al., 2001]
\end{tabular}

balance [Budyko, 1974], the "abcd" model for monthly or daily water balance [Thomas, 1981], and the Soil Conservation Service (SCS) curve number method for event-scale hydrologic runoff [SCS, 1972]. These hydrologic models have been successfully applied for water resources assessment at gauged and ungauged watersheds [Yadav et al., 2007]. Due to the variable roles of controlling factors on rainfall partitioning across time scales, these models originated from distinct concepts and are based on different representations of the hydrologic physical processes. As a result, the structure and mathematical representations of these models are quite different, particularly between the Budyko model and the SCS model. The Budyko model is based on the concept of water and energy limits, which demonstrates that water is the limiting factor on evaporation when energy is unlimited, and vice versa. By contrast, the SCS model is based on the proportionality concept of direct runoff and continuing abstraction which represents postponding infiltration.

For a given watershed, physical properties such as vegetation, soil, and topography co-evolve under climate driving forces [Sivapalan, 2005]. Hydrological responses, such as evaporation and runoff, across time scales are signatures from the co-evolution of natural systems [Newman et al., 2006; Wagener et al., 2010; Gentine et al., 2012; Wang and Wu, 2013; Harman and Troch, 2014]. Commonality, or linkage, exists among the behavior of rainfall partitioning across time scales and serves as an indicator of co-evolution. Therefore, the purpose of this paper is to recognize the general signature of rainfall partitioning by identifying the commonality of the three hydrologic models at the long-term, monthly, and event scales. The identified commonality, i.e., the generalized proportionality hypothesis, provides a hydrologic principle independent of any time scale from the Darwinian view, analogous to the role of the mass conservation principle from the Newtonian view. As a result of this study, a new single-parameter Budyko equation is derived for mean annual water balance, and a theoretical lower bound of the Budyko curve is identified.

\section{Hydrologic Models Across Varying Time Scales}

\subsection{Budyko Hypothesis for Mean Annual Water Balance}

In the mean annual or climatological water balance at the watershed scale, if water storage change is negligible, mean annual precipitation $(P)$ is partitioned into runoff $(Q)$ and evaporation $(E)$. Budyko [1958] postulated that the partitioning of precipitation, to the first order, was determined by the competition between available water $(P)$ and available energy measured by potential evaporation $\left(E_{p}\right)$. Based on the data from a large number of watersheds, Budyko [1974] proposed a relationship between the mean annual evaporation ratio $(E / P)$ and the mean annual potential evaporation ratio or climate aridity index $\left(E_{p} / P\right)$ :

$$
\frac{E}{P}=\left[\left(1-\exp \left(-\frac{E_{p}}{P}\right)\right) \frac{E_{p}}{P} \tanh \left(\frac{E_{p}}{P}\right)^{-1}\right]^{0.5}
$$

To incorporate the impact of other factors on water balance, various functional forms have been proposed or derived in the literature as shown in Table 1 [e.g., Turc, 1954; Mezentsev, 1955; Pike, 1964; Fu, 1981; Milly, 1994; Zhang et al., 2001; Milly and Dunne, 2002; Yang et al., 2008; Gerrits et al., 2009; Wang and Hejazi, 2011]. These models have advanced the understanding of the controls of vegetation, soil water storage, and climate seasonality on the water balance. The Budyko hypothesis for mean annual water balance results from the co-evolution of watershed vegetation and soils with climate [Gentine et al., 2012; Troch et al., 2013]. 


\subsection{The "abcd" Model for Monthly Water Balance}

The "abcd" model is a nonlinear monthly water balance model that was originally proposed by Thomas [1981] for national water assessment. This model has been utilized for monthly streamflow predictions taking rainfall and potential evaporation as inputs [Alley, 1985; Li and Sankarasubramanian, 2012]. The "abcd" model defines $W_{t}$ as available water and $Y_{t}$ as evaporation opportunity. Available water is the summation of precipitation during month $t$ and soil water storage at the beginning of month $t$; evaporation opportunity is the summation of actual evaporation during month $t$ and soil water storage at the end of month $t$. Evaporation opportunity $\left(Y_{t}\right)$ is postulated as a nonlinear function of available water $\left(W_{t}\right)$ :

$$
Y_{t}=\frac{W_{t}+b}{2 a}-\sqrt{\left(\frac{W_{t}+b}{2 a}\right)^{2}-\frac{W_{t} b}{a}}
$$

The parameter $a(0 \leq a \leq 1)$ represents the propensity for runoff to occur before the soils are fully saturated; the parameter $b$ is the upper bound of storage in the unsaturated zone above the groundwater table [Thomas, 1981]. Equation (2) is the key component of the "abcd" model and was proposed simply because the limits of the derivative of $Y$ should be 1 and 0 [Thomas, 1981]. Sankarasubramanian and Vogel [2002] modified the original model for understanding the role of soil water storage capacity on the annual water balance. The "abcd" model has been used to test the effectiveness of model calibration [Vogel and Sankarasubramanian, 2003] and diagnose model structure and performance [Martinez and Gupta, 2011].

\subsection{SCS Direct Runoff Model at the Event Scale}

Rainfall at the event scale is partitioned into direct runoff $\left(Q_{d}\right)$ and soil wetting $(W)$, where soil wetting includes initial abstraction $\left(I_{a}\right)$ and continuing abstraction $\left(F_{a}\right)$. The initial abstraction $I_{a}$ is the amount of water lost before direct runoff is generated, such as infiltration and rainfall interception by vegetation. After initial abstraction, the remaining water of $P-I_{a}$ is partitioned into $F_{a}$ and $Q_{d}$. The potential for continuing abstraction $(S)$ is a function of soil properties, land use and land cover, and the antecedent soil moisture condition. Given that $Q_{d}$ does not compete for $I_{a}$, the potential for direct runoff is $\left(P-I_{a}\right)$. The proportionality hypothesis of the SCS method is that the ratio of continuing abstraction to its potential is equal to the ratio of direct runoff to its potential value [SCS, 1972]:

$$
\frac{F_{a}}{S}=\frac{Q_{d}}{P-I_{a}}
$$

This proportionality equation was obtained based on observed data from a large number of watersheds [SCS, 1985].

\section{Generalized Proportionality Hypothesis}

The proportionality hypothesis of the SCS method has been generalized by Ponce and Shetty [1995] as follows. A certain amount of water $(Z)$ is partitioned into components $X$ and $Y$ (e.g., wetting and direct runoff in the SCS model). The quantity $X$ is constrained by its potential value denoted as $X_{P}$ (i.e., $S$ in the SCS model), and $X$ has a priority to meet the initial water demand of $X_{0}$, similar to $I_{a}$. The quantity $Y$ is constrained by the total water availability of $Z-X_{0}$. The partitioning of $Z$ is quantified by the generalized proportionality hypothesis:

$$
\frac{X-X_{0}}{X_{P}-X_{0}}=\frac{Y}{Z-X_{0}}
$$

The generalized proportionality hypothesis has been successfully applied for modeling the two-stage partitioning of rainfall and abstraction at the inter-annual scale [Ponce and Shetty, 1995; Sivapalan et al., 2011].

In this paper, it is hypothesized that the generalized proportionality concept is applicable to any time period, from event to long-term average scale. To illustrate this, we show that the generalized proportionality is the commonality of three Darwinian hydrologic models across three time scales: the SCS model at the event scale, the "abcd" model for monthly water balance, and the Budyko hypothesis for long-term water balance. The generalized proportionality hypothesis provides a methodology to develop Darwinian models 


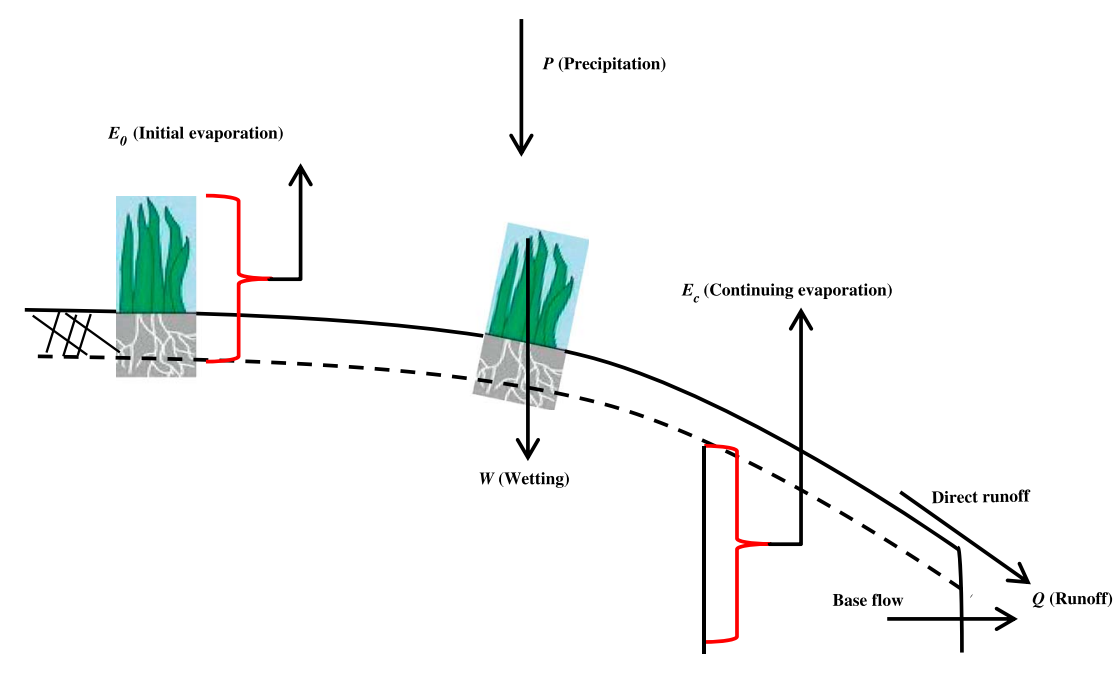

Figure 1. Partitioning of precipitation into evaporation (initial evaporation and continuing evaporation) and runoff.

that are independent of temporal scale and therefore serves a purpose similar to the water balance principle from the Newtonian view.

\section{Proportionality Application for Mean Annual Water Balance}

For mean annual water balance, water storage change is negligible, and precipitation is partitioned into evaporation and runoff. At the first stage of the partitioning, precipitation is partitioned into wetting and direct runoff [L'vovich, 1979]; at the second stage of the partitioning, wetting is partitioned into evaporation and base flow from groundwater discharge [Sivapalan et al., 2011]. Total runoff is the summation of direct runoff and base flow. As shown in Figure 1, a portion of wetting is only available for direct evaporation, such as that which occurs due to vegetation interception and water storage in top soils. Evaporation from this portion of wetting is defined as initial evaporation $\left(E_{0}\right)$. Following the initial abstraction concept of the SCS method, initial evaporation is represented as a percentage of wetting:

$$
E_{0}=\lambda W
$$

where $\lambda$ is the initial evaporation ratio and $\lambda W$ is the amount of water storage which is not available for competition between runoff and evaporation. The remaining rainfall $(P-\lambda W$ is partitioned into continuing evaporation $\left(E-E_{0}\right)$ and total runoff $(Q)$. Continuing evaporation is defined as the portion of evaporation that is lost through competition with runoff. For example, the interaction between root zone depth and the shallow water table dynamics affects the magnitude of continuing evaporation.

As precipitation increases unbounded, continuing evaporation is bounded by atmospheric evaporation demand and asymptotically approaches a constant value of $E_{p}-\lambda W$, where $E_{P}$ is mean annual potential evaporation aggregated from daily or monthly values. Runoff increases unbounded with precipitation but is constrained by $P-\lambda W$. Applying the generalized proportionality, we obtain:

$$
\frac{E-E_{0}}{E_{p}-\lambda W}=\frac{Q}{P-\lambda W}
$$

Substituting equation (5) and $Q=P-E$ (assuming no storage change on long time scales) into equation (6):

$$
\frac{E-\lambda W}{E_{p}-\lambda W}=\frac{P-E}{P-\lambda W}
$$

The ratio between evaporation and wetting is called the Horton index, $H=E / W$ [Horton, 1933; Troch et al., 2009], and is a catchment signature that is predominantly controlled by vegetation [Troch et al., 2009; 
Voepel et al., 2011]. Dividing the numerator and denominator of both sides of equation (7) by $P$ and substituting in $H$, we obtain:

$$
\frac{E / P-\frac{\lambda}{H} E / P}{E_{p} / P-\frac{\lambda}{H} E / P}=\frac{1-E / P}{1-\frac{\lambda}{H} E / P}
$$

The ratio between $\lambda$ and $H$ is denoted as $\varepsilon=\lambda / H$. Based on the definitions of $\lambda$ and $H, \varepsilon$ can be interpreted as the ratio between initial evaporation and total evaporation, $E_{0} / E$. A quadratic function for $\frac{E}{P}$ is obtained by manipulating equation (8):

$$
\varepsilon(2-\varepsilon)\left(\frac{E}{P}\right)^{2}-\left(1+\frac{E_{p}}{P}\right) \frac{E}{P}+\frac{E_{p}}{P}=0
$$

Since $\frac{E}{P}$ is positive and less than 1 , the root for $\frac{E}{P}$ is obtained as:

$$
\frac{E}{P}=\frac{1+E_{p} / P-\sqrt{\left(1+E_{p} / P\right)^{2}-4 \varepsilon(2-\varepsilon) E_{p} / P}}{2 \varepsilon(2-\varepsilon)}
$$

Equation (10) quantifies $\frac{E}{P}$ as a function of $\frac{E_{p}}{P}$ with a single parameter, $\varepsilon$. This equation is a single-parameter Budyko-type equation. The parameter $\varepsilon$ is the ratio of two dimensionless numbers, i.e., the ratio of the initial evaporation ratio to the Horton index. When $\varepsilon=1$, equation (10) represents the upper bound of the Budyko curve, i.e., $\frac{E}{P}=\frac{E_{p}}{P}$ when $\frac{E_{p}}{P} \leq 1$, and $\frac{E}{P}=1$ when $\frac{E_{p}}{P}>1$.

Like the Budyko-type equations in Table 1, equation (10) satisfies the boundary conditions:

$$
\begin{aligned}
& \frac{E}{P} \rightarrow 0 \text { when } \frac{E_{p}}{P} \rightarrow 0 \\
& \frac{E}{P} \rightarrow 0 \text { when } \frac{E_{p}}{P} \rightarrow \infty
\end{aligned}
$$

Observed data from real watersheds are typically clustered around the deterministic Budyko curve (equation (1)), which overlaps with the curve given by equation (10) when $\varepsilon$ is approximately 0.6. When $\varepsilon=\frac{2-\sqrt{2}}{2} \approx 0.29$, the functional form of equation (10) is the same as Fu's equation, with the parameter $\omega=2[F u, 1981]$.

\subsection{Lower Bound of E/P}

It should be noted that equation (10) can mathematically simulate the entire domain between the upper bound and the horizontal axis $(E / P=0)$. However, since initial evaporation $\left(E_{0}\right)$ cannot exceed total evaporation $(E)$, the physical range of $\varepsilon$ is between 0 and $1(0 \leq \varepsilon \leq 1)$. When $\varepsilon$ approaches zero, the limit of equation (10) can be obtained:

$$
\lim _{\varepsilon \rightarrow 0} \frac{E}{P}=\left[1+\left(\frac{E_{p}}{P}\right)^{-1}\right]^{-1}
$$

Equation (12) is the same as the Turc equation with $n=1$ [Turc, 1954] and the equation by Zhang et al. [2001] with $w=0$. Setting $\varepsilon=0$ is equivalent to setting $E_{0}=0$, in which case equation (6) reduces to the following:

$$
\frac{E}{E_{p}}=\frac{Q}{P}
$$

As a result, the lower bound of the Budyko curve corresponds to the condition when the ratio of evaporation to potential evaporation equals the runoff coefficient. The lower bound is equivalent to the constraint of $\frac{E}{E_{p}}=\frac{Q}{P}$.

The theoretical lower bound of $E / P$ is compared with reported data from real watersheds in the literature. Figure 2a plots the data for over 470 watersheds around the world from Zhang et al. [2004], and the lower 

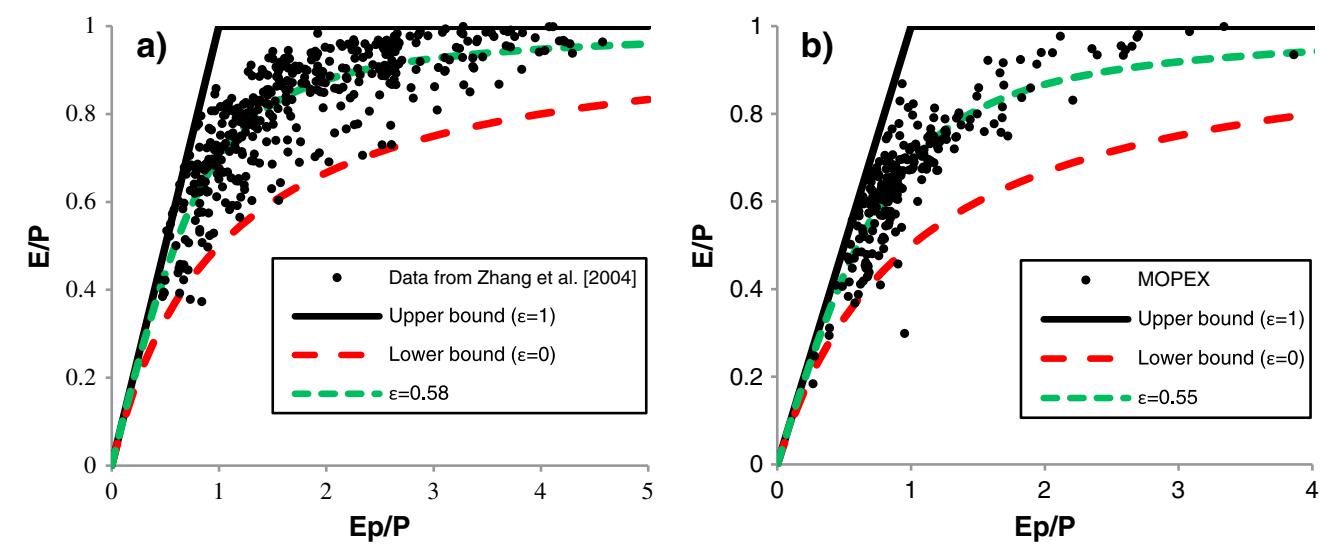

Figure 2. The theoretical lower and upper bounds of the Budyko curve and observed $E / P$ and $E_{p} / P$ data in watersheds: (a) around the world [Zhang et al., 2004], and (b) Model Parameter Estimation Experiment (MOPEX) data set. Equation (10) is plotted in both cases with the respective best fitted values for $\varepsilon$.

bound is found to accurately constrain the vast majority of the data points. The best fit for these data points is achieved with equation (10) when $\varepsilon=0.58$, as is also shown in Figure $2 \mathrm{a}$, where the fitted relationship overlaps with the deterministic Budyko curve given by equation (1). An additional 246 watersheds from the Model Parameter Estimation Experiment (MOPEX) data set [Duan et al., 2006] provide a second data set for verifying the lower bound, as is shown in Figure $2 b$, along with the best fit curve of equation (10) where $\varepsilon=0.55$. This second data set is also nearly entirely constrained by the theoretical lower bound; of the 246 watersheds in this data set, 242 are located above the lower bound determined by the proportionality hypothesis. The reported watershed data in other studies, using the equations in Table 1 , are also located above the lower bound with a few exceptions [Yang et al., 2007; Roderick and Farquhar, 2011; Donohue et al., 2011].

\subsection{Vegetation and Rainfall Frequency Control on $\varepsilon$}

As discussed earlier, the parameter $\varepsilon$ in equation (10) has a physical meaning from the process perspective. From the soil wetting perspective, $\varepsilon$ can be interpreted as the ratio between initial evaporation ratio $(\lambda)$ and the Horton index $(H)$. From the evaporation perspective, $\varepsilon$ is the ratio between initial evaporation and total evaporation, where initial evaporation is the component of the wetting which is not available for runoff competition. Here, the physical control on $\varepsilon$ is analyzed through the dimensionless numbers $\lambda$ and $H$.

The Horton index provides a measure of water use efficiency of vegetation in response to change in precipitation [Brooks et al., 2011]. The Horton index is relatively constant from year to year despite
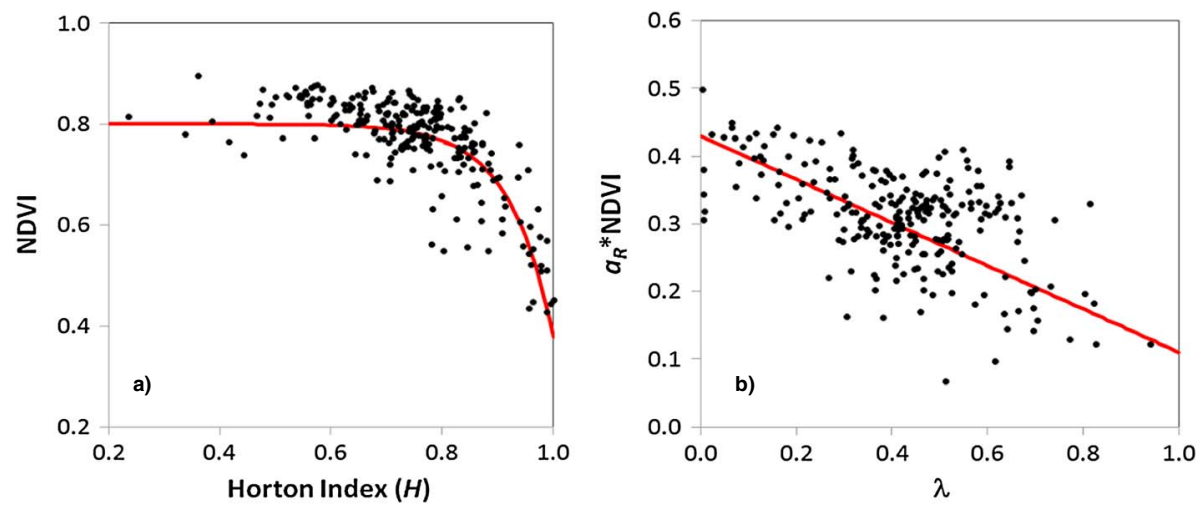

Figure 3. (a) The vegetation control (Normalized Difference Vegetation Index (NDVI)) on the Horton index, and the fitted red line represented by $N D V I=0.8\left(1-\mathrm{e}^{-12.82(1.05-\mathrm{H})}\right) ;(\mathrm{b})$ the vegetation and rainfall frequency $\left(\alpha_{R}\right)$ control on $\lambda=E_{0} / W$, and the fitted red line represented by $\alpha_{R} \cdot N D V I=0.43-0.32 \lambda$. 
fluctuations in annual precipitation, indicating that vegetation adapts to lower water availability by increasing water use efficiency [Troch et al., 2009]. In this study, soil wetting is computed by taking the difference between precipitation and direct runoff, which is obtained by base flow separation [Sivapalan et al., 2011]; bimonthly Normalized Difference Vegetation Index (NDVI) for the MOPEX watersheds are obtained from the satellite remote sensing data [Tucker et al., 2005]. Figure 3a presents the relation between average value of annual maximum NDVI and the Horton index, and the pattern is the same as the one reported by Voepel et al. [2011]. Water use efficiency of vegetation, represented by the Horton index, is close to 1 in water-limited regions.

The initial evaporation ratio $(\lambda)$ is the ratio of initial evaporation $\left(E_{0}\right)$ to total soil wetting $(W)$. Vegetation affects both soil wetting and initial evaporation. $W$ increases with NDVI as shown in Voepel et al. [2011], and $E_{0}$ may also increase with NDVI since interception loss increases with vegetation coverage. Over shorter time scales, $E_{0}$ is affected by the frequency of rainfall events. To evaluate the impact of rainfall variability on $\lambda$, the long-term average fraction of rainy days is computed for the MOPEX watersheds. The fraction of rainy days is computed from daily rainfall data as the ratio between the number of rainy days $\left(N_{R}\right)$ and the total number of days in a year $(N)$. As shown in Figure $3 b$, the initial evaporation ratio increases when $\alpha_{R}$. DVI declines. Therefore, soil wetting increases faster than initial evaporation when NDVI increases.

In summary, the dominant controlling factors on $\varepsilon$ are vegetation and rainfall. The physical meaning of $\varepsilon$ is the ratio of initial evaporation, which is not through the competition process with runoff such as evaporation from vegetation interception and top soil, to total evaporation. The magnitude of $\varepsilon$ decreases with increasing $\alpha_{R}$. The control of vegetation on $\varepsilon$ is complex because both $\lambda$ and $H$ decline with increasing NDVI. The relationship between $\varepsilon$ and NDVI is non-monotonic since vegetation affects the processes of wetting, initial evaporation, and total evaporation.

\section{A Temporal Pattern for Darwinian Hydrologic Models}

Dividing by $W_{t}$ on both sides of equation (2), the key equation of the "abcd" model can be written as:

$$
\frac{Y_{t}}{W_{t}}=\frac{1+\frac{b}{W_{t}}-\sqrt{\left(1+\frac{b}{W_{t}}\right)^{2}-4 a \frac{b}{W_{t}}}}{2 a}
$$

This equation has the same functional form as equation (10). Over a monthly period, $W_{t}$ is partitioned into $Y_{t}$ and runoff, and $b$ is the potential value of $Y_{t}$. Therefore, the concept of the "abcd" model is the same as the SCS and Budyko models, and equation (14) can be obtained from the generalized proportionality principle. As the above mentioned, the generalized proportionality is the commonality between the SCS and Budyko models, since the Budyko equation can be derived from the generalized proportionality hypothesis originating from the SCS model. In summary, the generalized proportionality hypothesis is identified as the commonality of the three Darwinian hydrologic models: the Budyko model for mean annual water balance, the "abcd" model for monthly water balance, and the SCS model for direct runoff at the event scale.

\section{Conclusions and Future Research}

In this work, the generalized proportionality hypothesis has been identified as the commonality of three hydrologic models across a range of time scales: the Budyko model at the long-term scale, the "abcd" model at the monthly scale, and the SCS model at the event scale. The Newtonian hydrologic modeling approach is independent of time scale; the generalized proportionality provides a hydrologic principle independent of time scales from Darwinian view. This commonality among rainfall partitioning across time scales is a signature of the co-evolution of climate, vegetation, soil, and topography as well as hydrologic responses. A single-parameter Budyko-type equation was derived based on the generalized proportionality hypothesis: the ratio of continuing evaporation to its potential equals the ratio of runoff to its potential.

The temporal pattern of water balance or proportionality hypothesis emerges from the analysis of observed data based on the Darwinian approach. Reliable generalization of the pattern calls for identifying the underlying mechanisms based on the Newtonian approach in order to go beyond pattern to process. This 
research provides a basis for the synthesis of Newtonian and Darwinian approaches, presents opportunities for important progress in hydrologic research [Sivapalan, 2005; Harman and Troch, 2014; Chen et al., 2013], and could also expedite progress in other disciplines of geosciences [Harte, 2002].

In practice, spatial or temporal patterns and process-based equations could co-exist in hydrologic model development. Laws or patterns based on the Darwinian approach could provide one component of a developed hydrologic model when Newtonian modeling is not achievable for some processes due to the limitation of observations or knowledge of mechanisms. Future research will investigate the linkage of rainfall partitioning between the event scale and long-term scale from a hydrologic processes view. Model structures, capturing temporal or spatial patterns and obeying the Newtonian laws, could be developed for reliable predictions.

Acknowledgments

This research was funded in part under Award NA10NOS4780146 from the National Oceanic and Atmospheric Administration (NOAA) Center for Sponsored Coastal Ocean Research (CSCOR) and Award NA10OAR4170079 from Florida Sea Grant. Data supporting Figure 2 are obtained from NOAA National Weather Service MOPEX data set (http://www.nws.noaa.gov/oh/ mopex/mo_datasets.htm) and Zhang et al. [2004]. The authors acknowledge the Editor (Dr. Bayani Cardenas) and the two anonymous reviewers for their very constructive comments and suggestions that have led to substantial improvements over an earlier version of the manuscript.

The Editor thanks two anonymous reviewers for assistance in evaluating this manuscript.

\section{References}

Alley, W. M. (1985), Water balance models in one-month-ahead streamflow forecasting, Water Resour. Res., 21(4), 597-606, doi:10.1029/ WR021i004p00597.

Beven, K. J., and M. J. Kirkby (1979), A physically based variable contributing area model of catchment hydrology, Hydrol. Sci. Bull., 24, 43-69. Blöschl, G., and M. Sivapalan (1995), Scale issues in hydrological modelling: A review, Hydrol. Process., 9, 251-290, doi:10.1002/hyp.3360090305.

Brooks, P. D., P. A. Troch, M. Durcik, E. Gallo, and M. Schlegel (2011), Quantifying regional scale ecosystem response to changes in precipitation: Not all rain is created equal, Water Resour. Res., 47, W00J08, doi:10.1029/2010WR009762.

Budyko, M. I. (1958), The Heat Balance of the Earth's Surface, translated from Russian by N. A. Stepanova, 259 pp., U.S. Dep. of Commer., Washington, D. C.

Budyko, M. I. (1974), Climate and Life, 508 pp., Academic Press, New York.

Chen, X., N. Alimohammadi, and D. Wang (2013), Modeling interannual variability of seasonal evaporation and storage change based on the extended Budyko framework, Water Resour. Res., 49, 6067-6078, doi:10.1002/wrcr.20493.

Choudhury, B. J. (1999), Evaluation of an empirical equation for annual evaporation using field observations and results from a biophysical model, J. Hydrol., 216, 99-110.

Donohue, R. J., M. L. Roderick, and T. R. McVicar (2011), Assessing the differences in sensitivities of runoff to changes in climatic conditions across a large basin, J. Hydrol., 406(3-4), 234-244.

Duan, Q., et al. (2006), The Model Parameter Estimation Experiment (MOPEX): An overview of science strategy and major results from the second and third workshops, J. Hydrol., 320(1-2), 3-17.

Dunne, T., and R. D. Black (1970), Partial area contributions to storm runoff in a small New England watershed, Water Resour. Res., 6(5), 1296-1311, doi:10.1029/WR006i005p01296.

Fu, B. P. (1981), On the calculation of the evaporation from land surface [in Chinese], Sci. Atmos. Sin., 5(1), 23-31.

Gentine, P., D. Entekhabi, and J. Polcher (2010), Spectral behaviour of a coupled land-surface and boundary layer system, Boundary Layer Meteorol., 134, 157-180.

Gentine, P., P. D'Odorico, B. R. Lintner, G. Sivandran, and G. Salvucci (2012), Interdependence of climate, soil, and vegetation as constrained by the Budyko curve, Geophys. Res. Lett., 39, L19404, doi:10.1029/2012GL053492.

Gerrits, A. M. J., H. H. G. Savenije, E. J. M. Veling, and L. Pfister (2009), Analytical derivation of the Budyko curve based on rainfall characteristics and a simple evaporation model, Water Resour. Res., 45, W04403, doi:10.1029/2008WR007308.

Harman, C., and P. A. Troch (2014), What makes Darwinian hydrology "Darwinian"? Asking a different kind of question about landscapes, Hydrol. Earth Syst. Sci., 18, 417-433, doi:10.5194/hess-18-417-2014.

Harte, J. (2002), Toward a synthesis of the Newtonian and Darwinian worldviews, Phys. Today, 55, 29, doi:10.1063/1.1522164.

Horton, R. E. (1933), The role of infiltration in the hydrologic cycle, Trans. AGU, 14, 446-460.

Li, W., and A. Sankarasubramanian (2012), Reducing hydrologic model uncertainty in monthly streamflow predictions using multimodel combination, Water Resour. Res., 48, W12516, doi:10.1029/2011WR011380.

L'vovich, M. I. (1979), World Water Resources and Their Future, 415 pp., AGU, Washington, D. C.

Martinez, G. F., and H. V. Gupta (2011), Hydrologic consistency as a basis for assessing complexity of monthly water balance models for the continental United States, Water Resour. Res., 47, W12540, doi:10.1029/2011WR011229.

Mezentsev, V. S. (1955), More on the calculation of average total evaporation, Meteorol. Gidrol., 5, 24-26.

Milly, P. C. D. (1994), Climate, soil water storage, and the average annual water balance, Water Resour. Res., 30, 2143-2156, doi:10.1029/ 94 WR00586.

Milly, P. C. D., and K. A. Dunne (2002), Macroscale water fluxes 2. Water and energy supply control of their interannual variability, Water Resour. Res., 38(10), 1206, doi:10.1029/2001WR000760.

Newman, B. D., B. P. Wilcox, S. R. Archer, D. D. Breshears, C. N. Dahm, C. J. Duffy, N. G. McDowell, F. M. Phillips, B. R. Scanlon, and E. R. Vivoni (2006), Ecohydrology of water limited environments: A scientific vision, Water Resour. Res., 42, W06302, doi:10.1029/2005WR004141.

Pike, J. G. (1964), The estimation of annual runoff from meteorological data in a tropical climate, J. Hydrol., 2, 116-123.

Ponce, V. M., and A. V. Shetty (1995), A conceptual model of catchment water balance. 1. Formulation and calibration, J. Hydrol., 173, 27-40.

Roderick, M. L., and G. D. Farquhar (2011), A simple framework for relating variations in runoff to variations in climatic conditions and catchment properties, Water Resour. Res., 47, W00G07, doi:10.1029/2010WR009826.

Sankarasubramanian, A., and R. M. Vogel (2002), Annual hydroclimatology of the United States, Water Resour. Res., 38(6), 1083, doi:10.1029/ 2001WR000619.

Sivapalan, M. (2005), Patterns, process and function: Elements of a unified theory of hydrology at the catchment scale, in Encyclopedia of Hydrological Sciences, edited by M. G. Anderson, vol. 1, part 1, chap. 13, p. 193, John Wiley, Chichester, U. K.

Sivapalan, M., M. A. Yaeger, C. J. Harman, X. Xu, and P. A. Troch (2011), Functional model of water balance variability at the catchment scale, 1: Evidence of hydrologic similarity and space-time symmetry, Water Resour. Res., 47, W02522, doi:10.1029/2010WR009568.

Thomas, H. A. (1981), Improved methods for national water assessment: Final report, U.S. Geol. Surv. Water Resour. Contract WR15249270, 44 pp. 
Troch, P. A., G. Carrillo, M. Sivapalan, T. Wagener, and K. Sawicz (2013), Climate-vegetation-soil interactions and long-term hydrologic partitioning: signatures of catchment co-evolution, Hydrol. Earth Syst. Sci., 17, 2209-2217.

Troch, P. A., G. F. Martinez, V. R. N. Pauwels, M. Durcik, M. Sivapalan, C. Harman, P. D. Brooks, H. Gupta, and T. Huxman (2009), Climate and vegetation water use efficiency at catchment scales, Hydrol. Process., 23(16), 2409-2414.

Tucker, C. J., J. E. Pinzon, M. E. Brown, D. Slayback, E. W. Pak, R. Mahoney, E. Vermote, and N. El Saleous (2005), An extended AVHRR 8-km NDVI data set compatible with MODIS and SPOT vegetation NDVI data, Int. J. Remote Sens., 26(20), 4485-5598.

Turc, L. (1954), Le bilan d'eau des sols: Relation entre la précipitation, l'évaporation et l'écoulement, Ann. Agron., 5, 491-569.

U.S. Department of Agriculture Soil Conservation Service (SCS) (1972), National Engineering Handbook, Section 4, Hydrology, U.S. Government Printing Office, Washington, D. C.

U.S. Department of Agriculture Soil Conservation Service (SCS) (1985), National Engineering Handbook, Section 4: Hydrology, U. S. Government Printing Office, Washington, D. C.

Voepel, H., B. Ruddell, R. Schumer, P. A. Troch, P. D. Brooks, A. Neal, M. Durcik, and M. Sivapalan (2011), Quantifying the role of climate and landscape characteristics on hydrologic partitioning and vegetation response, Water Resour. Res., 47, W00J09, doi:10.1029/ 2010 WR009944.

Vogel, R. M., and A. Sankarasubramanian (2003), Validation of a watershed model without calibration, Water Resour. Res., 39(10), 1292, doi:10.1029/2002WR001940.

Wagener, T., M. Sivapalan, P. A. Troch, B. L. McGlynn, C. J. Harman, H. V. Gupta, P. Kumar, P. S. C. Rao, N. B. Basu, and J. S. Wilson (2010), The future of hydrology: An evolving science for a changing world, Water Resour. Res., 46, 1-10, doi:10.1029/2009WR008906.

Wang, D., and M. Hejazi (2011), Quantifying the relative contribution of the climate and direct human impacts on mean annual streamflow in the contiguous United States, Water Resour. Res, 47, W00J12, doi:10.1029/2010WR010283.

Wang, D., and L. Wu (2013), Similarity of climate control on base flow and perennial stream density in the Budyko framework, Hydrol. Earth Syst. Sci., 17, 315-332.

Yadav, M., T. Wagener, and H. Gupta (2007), Regionalization of constraints on expected watershed response behavior for improved predictions in ungauged basins, Adv. Water Resour., 30, 1756-1774, doi:10.1016/j.advwatres.2007.01.005.

Yang, D., F. Sun, Z. Liu, Z. Cong, G. Ni, and Z. Lei (2007), Analyzing spatial and temporal variability of annual water-energy balance in nonhumid regions of China using the Budyko hypothesis, Water Resour. Res., 43, W04426, doi:10.1029/2006WR005224.

Yang, H., D. Yang, Z. Lei, and F. Sun (2008), New analytical derivation of the mean annual water-energy balance equation, Water Resour. Res. 44, W03410, doi:10.1029/2007WR006135.

Zhang, L., W. R. Dawes, and G. R. Walker (2001), Response of mean annual evapotranspiration to vegetation changes at catchment scale, Water Resour. Res., 37(3), 701-708, doi:10.1029/2000WR900325.

Zhang, L., K. Hickel, W. R. Dawes, F. H. S. Chiew, A. W. Western, and P. R. Briggs (2004), A rational function approach for estimating mean annual evapotranspiration, Water Resour. Res., 40, W02502, doi:10.1029/2003WR002710. 